Proc. Indian Acad. Sci. (Earth Planet. Sci.), Vol, 90, Number 2, July 1981, pp. 125-140. $\odot$ Printed in India.

\title{
Short-period oscillations in outgoing longwave radiation over the summer monsoon region*
}

\author{
C MUTHUVEL \\ Department of Meteorology, University of Hawaii, Honolulu, \\ Hawaii 96822, USA \\ Present address : Department of Meteorology, University of Maryland, College \\ Park, Maryland 20742, USA
}

MS received 11 June 1980; revised 14 May 1981

\begin{abstract}
Empirical orthogonal function (EOF) analysis is applied to daily outgoing longwave radiation (OLR) data to identify the major modes of oscill. ation over the summer monsoon region $\left(7.5^{\circ} \mathrm{N}-32.5^{\circ} \mathrm{N}, 62.5^{\circ} \mathrm{E}-142.5^{\circ} \mathrm{E}\right.$ ) for two summers 1975 and 1977 , each consisting of 120 days from $18 \mathrm{May}$ through 14 September. Power spectrum analysis of time-dependent coefficients of the dominant eigenvectors exhibit spectral peaks in the long ( $<15$ days) and short (4-8 days) period ranges. A detailed study is confined to 4-8 day filtered OLR perturbations. Standard deviation patterns of filtered OLR show large intraseasonal variability in the activity of monsoon disturbances over the Bay of Bengal. Lag-correlations reveal systematic westward movement of 4-8 day OLR perturbations from the Western Pacific to the Bay of Bengal in both summers.

EOF analysis is also applied to 4-8 day filtered OLR data to further investigate possible teleconnections in disturbance activity between the Western Pacific and the Bay of Bengal. A compositing technique is utilized to detail the structural features (zonal wavelength and phase speed) of 4-8 day OLR disturbances. Composite diagrams for summer 1975 showed that OLR disturbances which originated near northeastern Burma moved westward with phase speed (wavelength) of about $3-4^{\circ}$ per day $\left(\sim 20-25^{\circ}\right.$ longitude) reaching maximum intensity in the Bay of Bengal. In summer 1977, the disturbance activity in the Bay of Bengal was associated with OLR perturbations which originated in the Western Pacific and moved westward across the South China Sea and Indochina with phase speed (wavelength) of above $8^{\circ}$ per day (40. longitude).
\end{abstract}

Keywords. Short-period oscillation; long wave radiation; summer-monsoon regions; orthogonal function.

\section{Introduction}

Meteorologists have long questioned whether monsoon disturbances (monsoon depressions, monsoon lows, etc.) form in situ over the Bay of Bengal or if weak westward propagating disturbances (coming from the east) intensify there. As long as four decades ago, Doraisamy lyer (1939) noticed that in many cases pressure falls occur in the Bay of Bengal either in situ or in association with the movement of low pressure areas from the east, which he considered as typhoon remnants. However, many Indian meteorologists belive that monsoon

*Contribution No. 80-04, Department of Meteorology, University of Hawaii 
depressions form in situ over the Bay of Bengal under "favourable" conditions. The tracks of monsoon depressions published by the India Meteorological Department (1964) and Ananthakrishnan and Bhatia (1960) showed that all tracks originated in the Bay of Bengal. Since satellite pictures do not usually show cloud clusters moving continuously from the Western Pacific, across Indochina and Burma to the Bay of Bengal (Wallace 1970), the in situ formation theory does find some support. In addition, Shukla (1978) based on his quasigeostrophic model, applied barotropic-baroclinic-CISK instability theory to investigate the cyclogenesis in the Bay of Bengal. He hypothesized that the terrain (by producing a monsoon trough at the Himalayan foothills) provides the "triggering" mechanism for the formation, and CISK provides the "driving" mechanism for the growth of monsoon depressions.

Following midlatitude cyclone development theories of Sutcliffe (1947) and Pettersen (1956), Koteswaram and George (1958, 1960) and Koteswaram and Bhaskara Rao (1963) presented evidence that a monsoon depression develops at sea level, when and where an area of positive vorticity advection in the upper troposphere becomes superimposed upon a pre-existing trough at sea level. This positive vorticity advection usually occurs to west of either a westward moving trough or a speed maximum in the upper tropospheric easterlies. Krishnamurti et al (1977) using 43 years of surface pressure data, proposed a downstream amplification mechanism. They illustrated this mechanism by the superposition of stationary longwaves with transient shortwaves from the Western Pacific. Krishnamurti and Bhalme (1976) recently made a comprehensive analysis on quasi-biweekly oscillations of the monsoon and considered monsoon fluctuations from the viewpoint of interhemispheric coupling. They reasoned that sequential happenings to various elements (including the Mascarene high, the tropical easterly jet, the Tibetan high, cross-equatorial low level jet, and dry and moist static stability of the lower troposphere over India) lead to $13 \cdot 1$ day oscillations in the monsoon system. According to them, this situation is presumed to comprise favourable conditions for the formation of monsoon depressions and the quasi-biweekly mode of rainfall in central India.

Many spectral studies have also been carried out. Keshavamurthy (1972) found 5-6 (7-9) day spectral peaks in the meridional wind component in the lower (middle) troposphere and examined their association with development of monsoon depressions and monsoon lows. Keshavamurthy (1972) and Murakami (1976) showed that oscillations in the monsoon system around 4-8 days roughly correspond to monsoon disturbances.

In this study, satellite observed longwave radiation data for two summers 1975 and 1977 are used to delineate characteristic features of shoit period (4-8 days) oscillations. In $\S \S 3$ and 4 possible teleconnections between the Bay of Bengal, the South China Sea, and the Western Pacific are exemplified. Also, the interannual variability (between the two summers) in structural features (zonal wavelength and phase speed) of 4-8 day period disturbances is detailed. These two summer monsoon seasons of 1975 and 1977 were considered to be good monsoons (from the rainfall point of view) by the Indian metcorologists (Raman et al 1980) 


\section{Data and computational procedures}

Twice daily outgoing longwave radiation (OLR) data provided by the National Oceanic and Atmospheric Administration's (NOAA) polar orbiting satellites are used. Daily OLR is a mean of morning and evening observations. Summers 1975 and 1977 are studied during a 120-day period from 18 May through 14 September. The OLR data we used here cover the summer monsoon region from $7.5^{\circ} \mathrm{N}$ to $32.5^{\circ} \mathrm{N}$, and $62.5^{\circ} \mathrm{E}$ to $142.5^{\circ} \mathrm{E}\left(2.5^{\circ}\right.$ latitude-longitude resolution).

The NOAA satellite measures outgoing IR in a narrow channel of the "atmospheric window" region ( $8-12 \mu \mathrm{m})$ and obtains the total OLR from the window radiance through regression coefficients. The window channel radiance is sensitive to surface temperature, and spatially and temporarily varying constituents such as aerosols. However, OLR largely reflects convective activity associated with disturbances, and provides continuous (time and space) coverage of their activity. In this study, OLR data was used to detail the nature (propagation, amplification) of monsoon disturbances over South and Southeast Asia.

Empirical orthogonal function (EOF) analysis has been used extensively in meteorology and oceanography (e.g.. Grimmer 1963; Kutzbach 1967; Weare 1977). It enables fields of highly correlated data to be represented adequately by a small number of eigenfunctions and their corresponding time coefficients. Unlike most orthogonal representations, these functions do not require a predetermined form but depend on the interrelationships within the data being analyzed. Simply stated, EOF analysis identifies the major modes of oscillations combined in both space and time, which account for most of the total variance. Most of the above mentioned papers employed EOF analysis to investigate climatology-related problems. Based on grid point OLR data during the three winters 1974-77, Murakami (1980 b and c) first applied EOF analysis to identify the principal components of temporal ( $<20$ days) oscillations (transient disturbances) over the Malaysia-Indonesia-Philippines region. The reader is directed to Murakami's papers for a complete description of EOF analysis, as only a brief outline will be presented here.

Let $f_{\mathrm{n}}$ be a $M$-component vector representing the $n$th observation. Then $f_{\mathrm{n}}$ may be expressed as follows:

$$
f_{\mathrm{u}}=\sum_{i=1}^{M} C_{\mathrm{i}, \mathrm{n}} e_{\mathrm{i}} \quad n=1,2, \ldots, N \quad,
$$

where $e_{\mathrm{i}}$ denotes the eigenvector associated with the $i$ th eigenvalue and $C_{\mathrm{i}, \mathrm{n}}$, the time-dependent coefficient of the $i$ th eigenvector for the $n$th observation. The total number of observations $N$, is equal to 120 for EOF analysis applied to OLR data in each summer (18 May through 14 September). Here $M$, the number of grid points under consideration is equal to 182 . We used a horizontal resolution of $2.5^{\circ}$ latitude by $5^{\circ}$ longitude [staggered grid, as shown in figure 3 (top)], which is sufficient to describe the structural features of synoptic scale disturbances with wavelengths greater than $2,000 \mathrm{~km}$. Prior to 
application of EOF analysis, the root mean square linear and quadrature trends in time were removed from the daily OLR data at each grid point. Thus the anomalies of $M$ variables are defined as departures from the trend of the corresponding variables. Each variable was then nondimensionalized (normalized) by dividing the anomalies by the mean of the standard deviation computed at all grid points. The use of normalized data ensures that the eigenvector fields reflect the real spatial distribution of OLR over the domain considered.

EOF analysis was then applied to OLR data for summers 1975 and 1977 with $N=120$ and $M=182$. The first five eigenvectors accounted for approximately $44 \%$, the first ten $\sim 63 \%$ and the first fifteen $\sim 74 \%$ of the total OLR variance in both summers.

To find periodicities associated with each mode, we applied power spectral analysis to time dependent coefficients $C_{i, n}$ for each year. The spectrum for the first eight eigenmodes is shown in figures 1 and 2. Following Zangil (1975) the product of power spectral density and frequency is plotted along the $y$-axis and logarithm of frequency is plotted along the $x$-axis. For modes higher than ten, the corresponding spectra exhibited spectral peaks in the very short period range (around 2 days) which is largely associated with computational errors due to poor (1-day) data resolution and hence is not shown. Furthermore the fractional variance explained by higher order modes (beyond the tenth) is, small.

In 1975, the spectrum for mode I shows a sharp peak at 30 days and another small peak at about 5 days, whereas mode 2 peaks at about 20 days. From mode 3 onward, one observes well-defined peaks in the 4-8 day range. In 1977 (figure 2), the first and second modes exhibit peaks at about 15 and 20 days, respectively. A minor peak at around 6 days can also be noticed in the first mode. Mode 3 shows a broad maximum in the spectrum combining both short and long periods. For modes higher than 4, distinct peaks in the period 4-8 days can be observed.* The above spectral picture depicts the general character of EOF analysis, wherein the first few modes usually reflect dominant long-period fluctuations with higher order modes being dominated by the next major periodicity in the fluctuations, here $4-8$ days. The characteristics of long period fluctuations of OLR (15-30 days) during summer has already been studied and reported by Murakami (1980a).

Only the characteristics of short period (4-8 days) OLR oscillations are studied here. To facilitate further study, the original $f n$ data is prefiltered for 4-8 days. Smoothed time series of data at $n$-time were obtained by:

$$
\bar{f}_{\mathrm{n}}=a\left(\mathrm{f}_{\mathrm{n}}-\mathrm{f}_{\mathrm{n}-2}\right)-b_{1} \overline{\mathrm{f}}_{\mathrm{n}-1}-b_{2} \bar{f}_{\mathrm{n}-2}, \quad n=1,2, \ldots, N
$$

\footnotetext{
*Using 80 years of surface pressure data, Paul and Sikka (1975) produced a table, which gave a frequency distribution of time intervals between two successive depressions. It suggests that a predominantly large number of monsoon depressions form in the interval ranging from 3 to 8 days.
} 
PERIOD (DAYS)
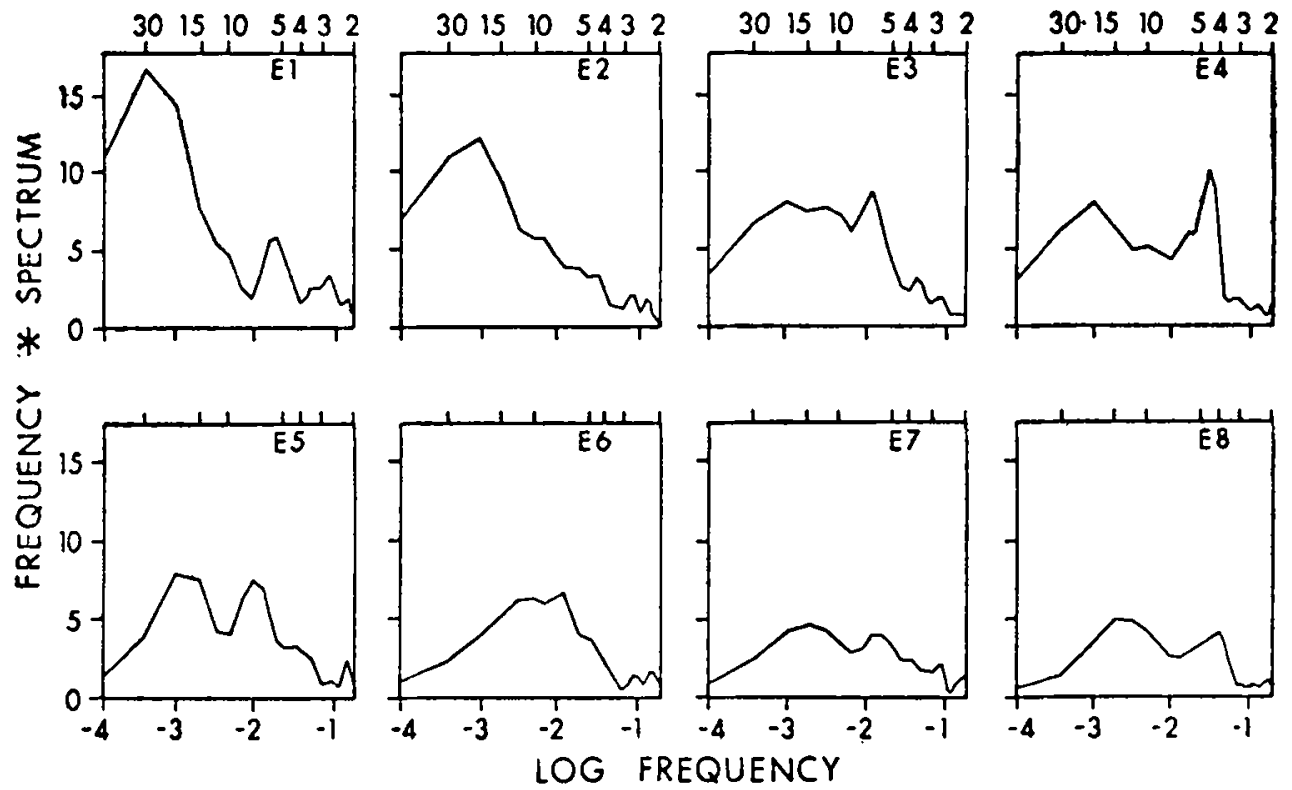

Figure 1. Power spectra of OLR time dependent coefficients $\left(C_{i}, n\right)$ for the first eight eigenvectors (E1-E8) for summer 1975. See text for information on the method of spectral depiction.

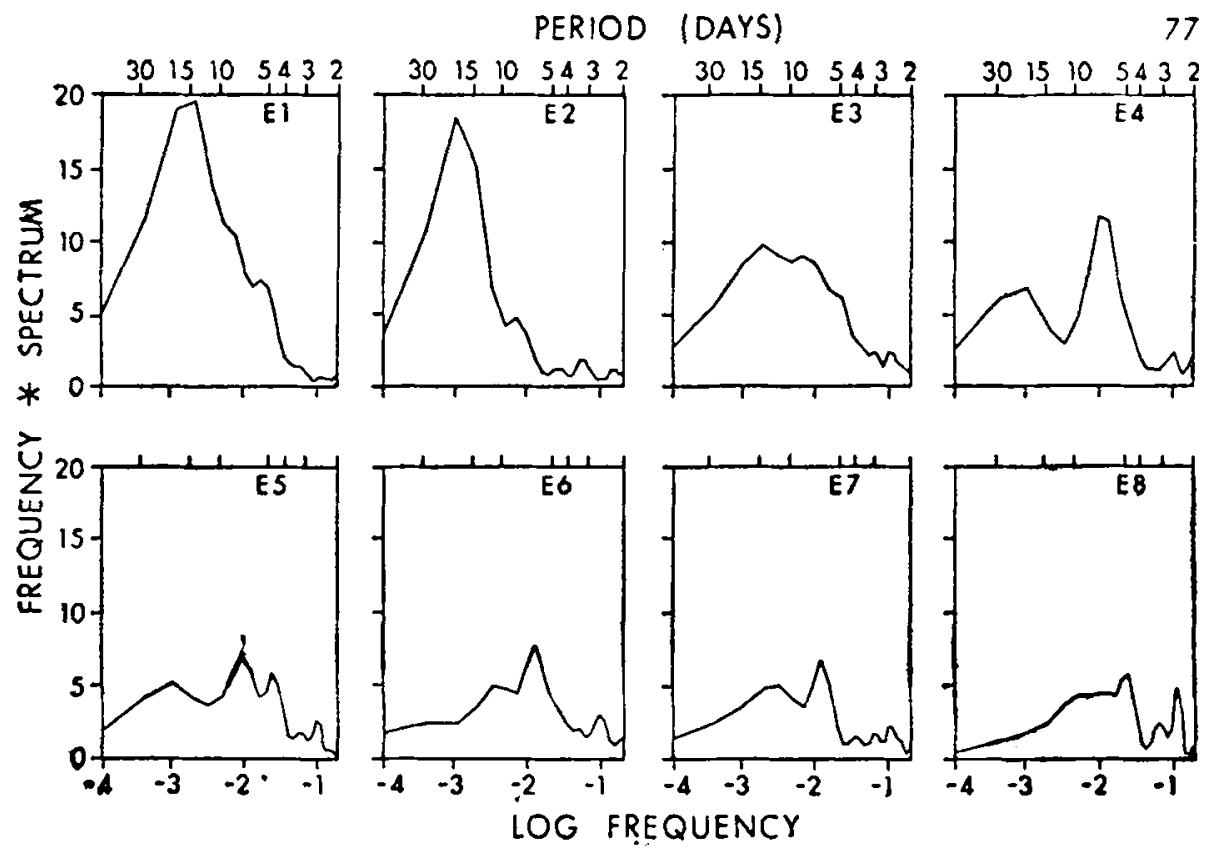

Figure 2. As in figure 1 except for summer 1977. 


$$
\begin{aligned}
& \text { where } a=\frac{2 \Delta \Omega}{4+2 \Delta \Omega+\Omega_{0}^{2}}, b_{1}=\frac{2\left(\Omega_{0}^{2}-4\right)}{4+2 \Delta \Omega+\Omega_{0}^{2}}, b_{2}=\frac{4-2 \Delta \Omega+\Omega_{0}^{2}}{4+2 \Delta \Omega+\Omega_{0}^{2}} \\
& \Delta \Omega=2\left|\frac{\sin \left(\omega_{1} \Delta T\right)}{1+\cos \left(\omega_{1} \Delta T\right)}-\frac{\sin \left(\omega_{2} \Delta T\right)}{1+\cos \left(\omega_{2} \Delta T\right)}\right|, \\
& \Omega_{0}^{2}=\frac{4 \sin \left(\omega_{1} \Delta T\right) \cdot \sin \left(\omega_{2} \Delta T\right)}{\left(1+\cos \left(\omega_{1} \Delta T\right)\right) \cdot\left(1+\cos \omega_{2} \Delta T\right)} \\
& \text { in which } \Delta T=1 \text { day, } \omega_{0}=\frac{2 \pi}{6 \text { days }}, \omega_{1}=\frac{2 \pi}{8 \text { days }} \\
& \text { and } \omega_{2}=\omega_{0}^{2} / \omega_{1}
\end{aligned}
$$

The above calculation procedure formulated by Shanks (1967) and modified by Murakami (1979) consists of two steps. First equation (2) is applied to compute tentative mean values for $f_{\mathrm{n}}$ from $n=3$ to $n=N$ by assuming that $\widetilde{f_{1}}=\widetilde{f_{2}}=0$. Then utilizing these mean values, the process is reversed in time to obtain the final $\bar{f}_{\mathrm{n}}$ values. Small boundary errors were detected for the first and last ten days of filtering. Hence, only a 90-day data period, excluding the first and last 15 days, was chosen for detailed analysis of $4-8$ day filtered data. For convenience, dates within this selected period will hereafter be referred to as being in the range 1-90 days (2 June through 30 August) rather than 16-105 days.

\section{Standard deviations and correlations}

Standard deviations $(\sigma)$ of 4-8 day filtered OLR data are computed for each summer (1975 and 1977). Summer 1975 (figure 3, top) standard deviations exceed 20 units $\left(\mathrm{Wm}^{-2}\right)$ over the Bay of Bengal region, congruent with the persistent activity of monsoon depressions and monsoon lows throughout the season. Regions with standard deviations exceeding 15 units occupy either side of the Philippine Islands. Minimum standard deviations are observed north of about $25^{\circ} \mathrm{N}$ with smallest values ( $<5$ units) over northwest India and Pakistan, where deep tropospheric downdraft persists over the heat low inhibiting cloud formation. The Arabian Sea is very weak in convective activity with small standard deviation values of less than 10 units.

Figure 3 indicates that the Bay of Bengal was equally active in both summer seasons. However, the region east of $100^{\circ} \mathrm{E}$ appears to have been more active in summer 1977 than summer 1975. The presence of a band of large standard deviations, extending zonally along about $20^{\circ} \mathrm{N}$ from the Western Pacific through the northern South China Sea to the Bay of Bengal, is a well-pronounced feature in summer 1977. This probably indicates that disturbances which formed in the Western Pacific are related in some way to those in the Bay of 


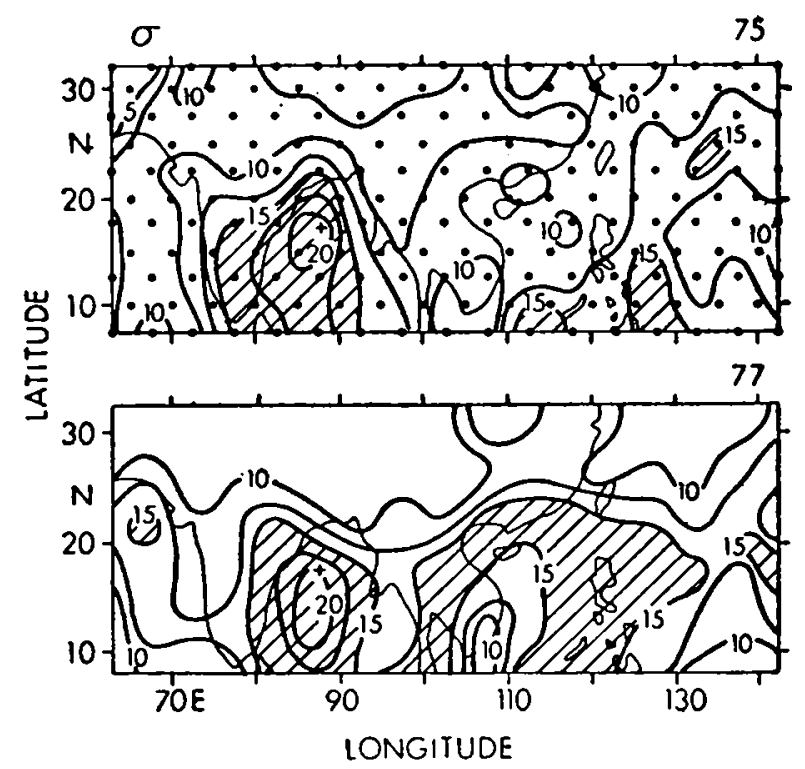

Figure 3. Standard deviation $(\sigma)$ of 4-8 day filtered OLR for summer 1975 (top) and summer 1977 (bottom) in Watts per sq. meter. Interval 2.5 units. Regions greater than 15 units are shaded. The horizontal distribution of data points used in analysis is show $n$ in top diagram.

Bengal. Another interesting feature is the existence of a narrow band of large standard deviation values running north-south enveloping the Malay peninsula in summer 1977. A comparison between figure 3 (top and bottom) indicates that large interannual changes in the activity of the summer monsoon takes place over the Indochina-Malay peninsula region.*

In an effort to investigate how 48 day OLR fluctuation vary in different parts of the monsoon region relative to activity in the Bay of Bengal, we chose a reference point at $87 \cdot 5^{\circ} \mathrm{E}, 17 \cdot 5^{\circ} \mathrm{N}$ (near head Bay), where standard deviation is largest in both summers. Zero-lag correlation coefficients $(\gamma)$ were computed between 4-8 day OLR fluctuations at the reference point and those at all grid points in the region. Computed results for both summers are shown in figure 4.

In summer 1975 (figure 4, top), a large region of positive correlation can be seen surrounding the reference point extending from the west coast of India to Burma. A fairly large area of negative correlations covers the Philippines and most of the South China Sea. The dominant feature present in summer 1975 and absent in 1977 is the existence of a north-south band of negative correlations over eastern Burma, Thailand and the Malay peninsula. In both summers, major parts of the Western Pacific (Arabian Sea) are in phase (out

*Wallace and Chang (1969), based on spectral analysis of $u$ and $v$ components of wind data averaged from surface to $550 \mathrm{mb}$ at selected trapical stations (Western Pacific), found large interannual variability in the 4-5 day spectral peaks. In one case (January-June 1964) they were even absent. 


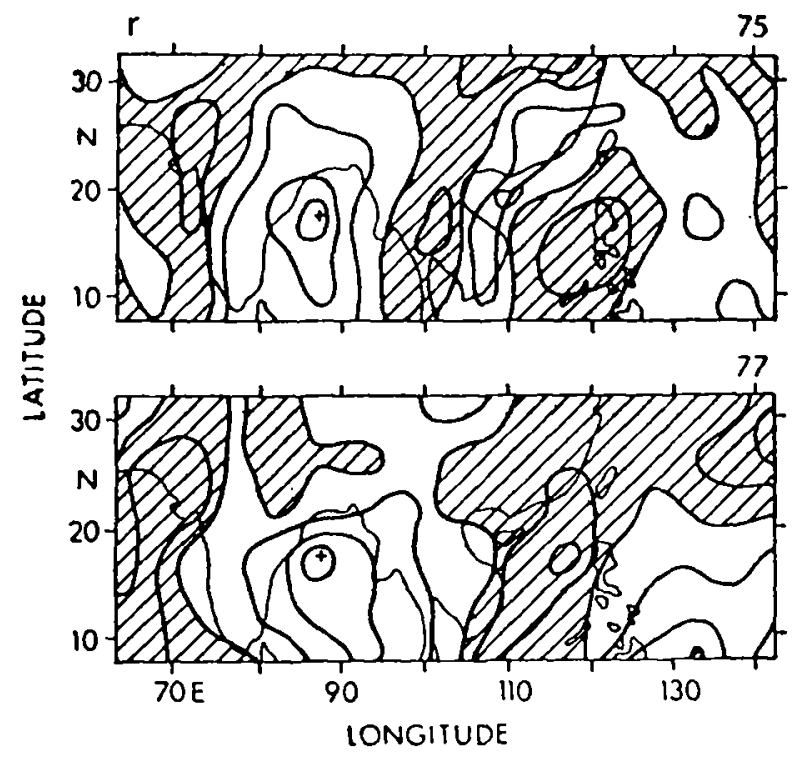

Figure 4. Correlation coefficients ( 0.3 intervals) between the 4-8 day filtered OLR at the reference point $\left(17.5^{\circ} \mathrm{N}, 87.5^{\circ} \mathrm{E}\right)$ and that at al] other points for summer 1975 (top) and summer 1977 (bottom). Shading indicates negative correlation regions.

of phase) with the Bay of Bengal region; namely, that whenever the Bay of Bengal is convectively active, the Western Pacific is also active while the Arabian Sea is inactive (or weak) during this time. In figure 4 the east-west alternation of positive and negative correlation zones equatorward of about $25^{\circ} \mathrm{N}$ indicates a wavelike character in tropical OLR fluctuations. In 1975, the pattern appears to be of short wavelength $\left(\sim 20-25^{\circ}\right.$ longitude). In comparison, the correlation pattern for summer 1977 clearly reflects a larger scale with a wavelength of about $40^{\circ}$ longitude.

In order to see how 4-8 day filtered OLR perturbations move in time, lagcorrelation diagrams were constructed at different latitudes for both summers. This was done by computing lag-correlations between 4-8 day filtered OLR at the reference point $\left(87 \cdot 5^{\circ} \mathrm{E}, 17 \cdot 5^{\circ} \mathrm{N}\right)$ and those at all grid points for lags -4 to +4 days at interval of 1 day. Figures 5 and 6 depict these lag-correlation diagrams at three latitudes; $22 \cdot 5^{\circ} \mathrm{N}, 17 \cdot 5^{\circ} \mathrm{N}$ and $12 \cdot 5^{\circ} \mathrm{N}$ for summers 1975 and 1977. At $17 \cdot 5^{\circ} \mathrm{N}$ and $12 \cdot 5^{\circ} \mathrm{N}$, clear westward movement can be noted with a phase speed of about $3-4^{\circ}$ per day in summer 1975 . Similar westward movement, aithough much less organized, is seen at $22 \cdot 5^{\circ} \mathrm{N}$. In summer 1977 , one observes pronounced westward movement occurring at all three latitudes, extending from the Western pacific to the Bay of Bengal and beyond, with a phase speed of about $8^{\circ}$ per day (which is twice as large as the phase speed in 1975).

In summary, the zonal wavelength of 4-8 day OLR perturbations in summer 1977 is around $40^{\circ}$ longitude with an easterly phase speed of about $8^{\circ}$ per day. In summer 1975, the corresponding wavelength was definitely shorter $\left(\sim 20-25^{\circ}\right)$ 

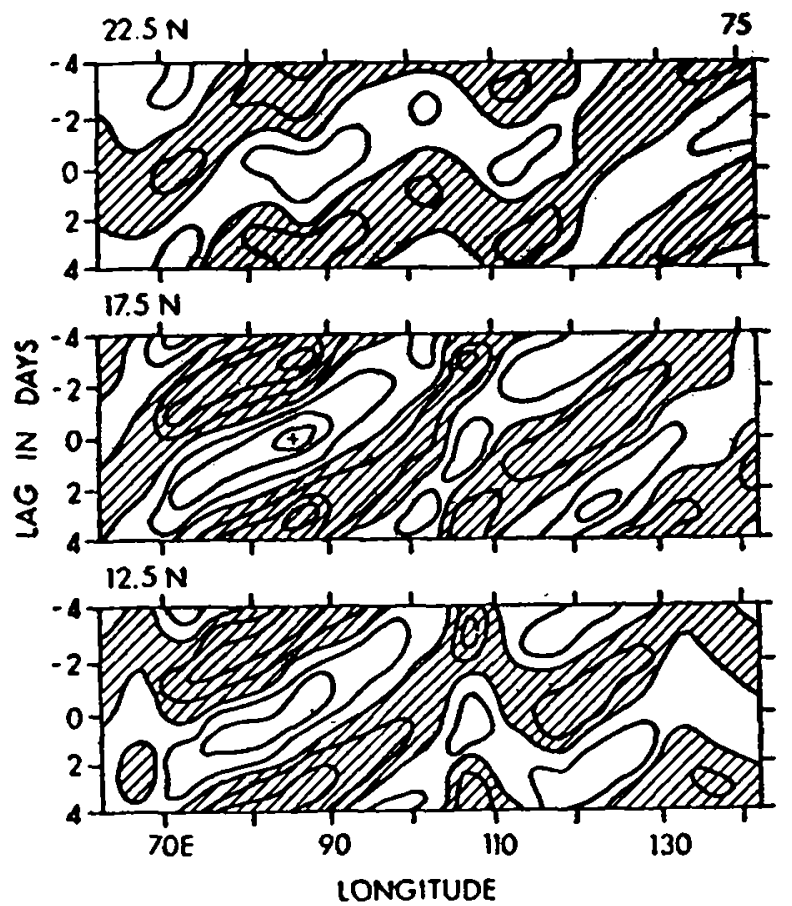

Figure 5. Longitude-lag correlation (0.3 intervals) for lags -4 to +4 days for summer 1975 at $22.5^{\circ} \mathrm{N}, 17.5^{\circ} \mathrm{N}$ and $12.5^{\circ} \mathrm{N}$. Shading indicates negative correlations.
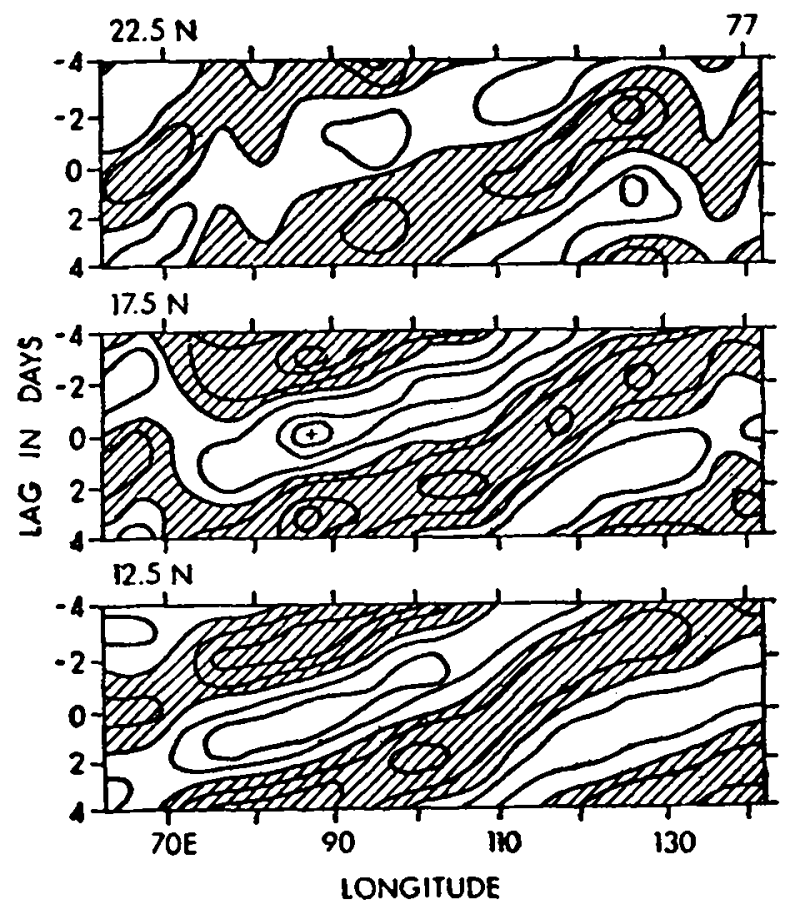

Figure 6. As in figure 5 except for summer 1977. 
than it was in 1977 , with an easterly phase speed of about $3-4^{\circ}$ per day. This reflects large interannual changes in the zonal phase speed and wavelength of 4-8 day OLR perturbations over the summer monsoon region. This point will be further elaborated in the next section.

\section{EOF analysis and composite charts for $\mathbf{4 - 8}$ day filtered OLR fields}

Correlation coefficients (figures 5 and 6) do not necessarily reflect the changes in the intensity of OLR perturbations as they propagate westward. To further detail OLR movement and intensity, and to investigate the structural features of OLR perturbations, we applied EOF analysis to the filtered OLR data for summers 1975 and 1977 with $M=182$ and $N=90$.

Application of EOF analysis on 4-8 day filtered OLR yielded 182 eigenmodes of which the first five (ten) eigenmodes explained approximately $63 \%(83 \%)$ of the total variance during both summers. The first two eigenvector patterns (hereafter referred to as E1 and E2) are shown in figures 7 and 8 . E1 pattern (figure 7, top) of summer 1975 is characterized by large positive* anomalies over the central Bay of Bengal covering most of south and northeast India. Another interesting feature in E1 pattern is the presence of a continuous band of positive anomalies extending from the northwestern Pacific to the Bay of Bengal across Indochina. In the $\mathrm{E} 2$ pattern (figure 7 , bottom), a zone of large positive anomalies is centered over the head Bay of Bengal and extends eastward through Indochina to the eastern coasts of continental Asia. In summer 1977 (figure 8), both eigenvector patterns E1 and E2 clearly reflect wavelike features with wavelengths of about $4,000 \mathrm{~km}$.

A compositing technique was utilized to investigate the phase relationships between changes in OLR perturbations over different parts of the region. As mentioned earlier, approximately $83 \%$ of the total variance in 4-8 day filtered OLR data is retained when representation is made summing over the first ten eigenmodes. The horizontal resolution ( $5^{\circ}$ longitude by $2 \cdot 5^{\circ}$ latitude) of OLR data used in EOF analysis may not be adequate to detail higher order eigenvectors (beyond the tenth), since these modes exhibit horizontal scales of less than $2,000 \mathrm{~km}$. Furthermore, these higher modes (greater than ten) contribute little to the total variance of 4-8 day filtered OLR oscillations. Therefore, due to questionable accuracy of these higher order modes, truncated 4-8 day OLR data are computed by considering the first ten eigenvectors in equation (1). The compositing technique consists of assigning an appropriate category (numbered 1 to 9 ) to truncated OLR data in each of the 4-8 day cycles. The categories were assigned using the truncated (eigenmodes 1 to 10 ) time series of data at $17.5^{\circ} \mathrm{N}, 87.5^{\circ} \mathrm{E}$ which is shown in figure 9. Category 1 is centred at the time of the maximum value of OLR, while category 5 is centred at the time of the minimum value. Category 9 coincides with category 1 . The remaining categories, 2 to 4 and 6 to 8 , occupy intermediate OLR values. Twelve 4-8 day cycles (which cover nearly the entire summer) were selested from figure 9 for each year. Category means were then computed at all grid points for each

*The sign of eigenvector pattern is interchangeable. 


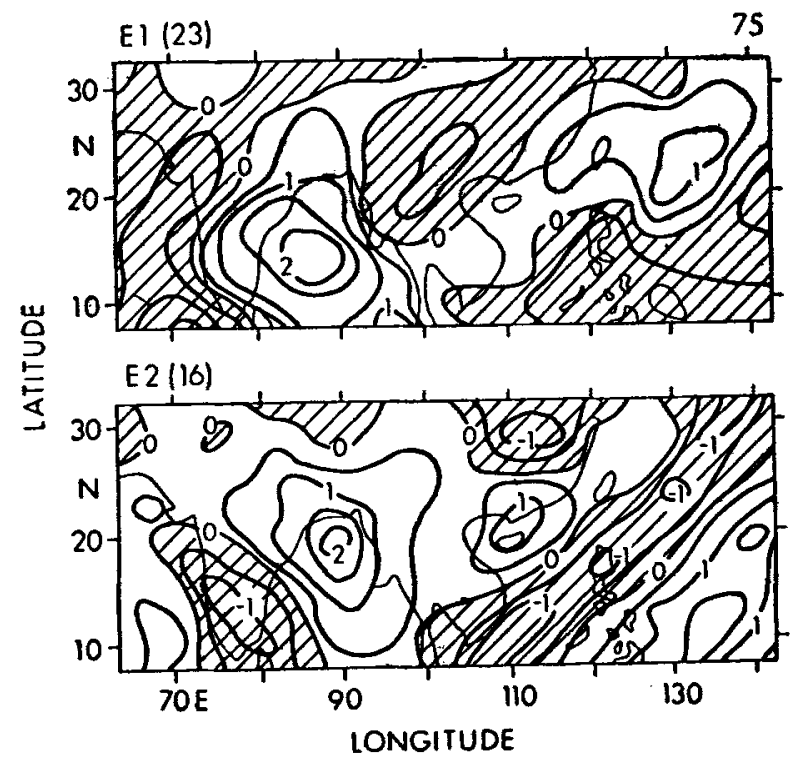

Figure 7. First two eigenvector patterns of 4-8 day filtered OLR for summer 1975. Shading indicates negative regions. Percent of total variance explained by each mode is shown in brackets.

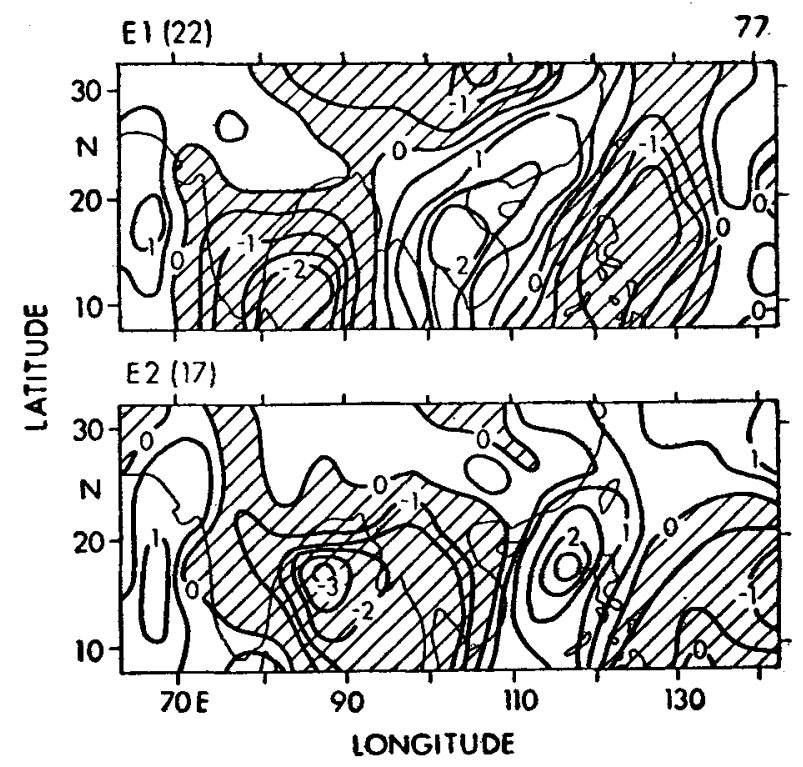

Figure 8. As in figure 7 except for summer 1977.

category. Since categories were defined only at one reference point, phase relationships can be examined by comparing category means at various grid points. 


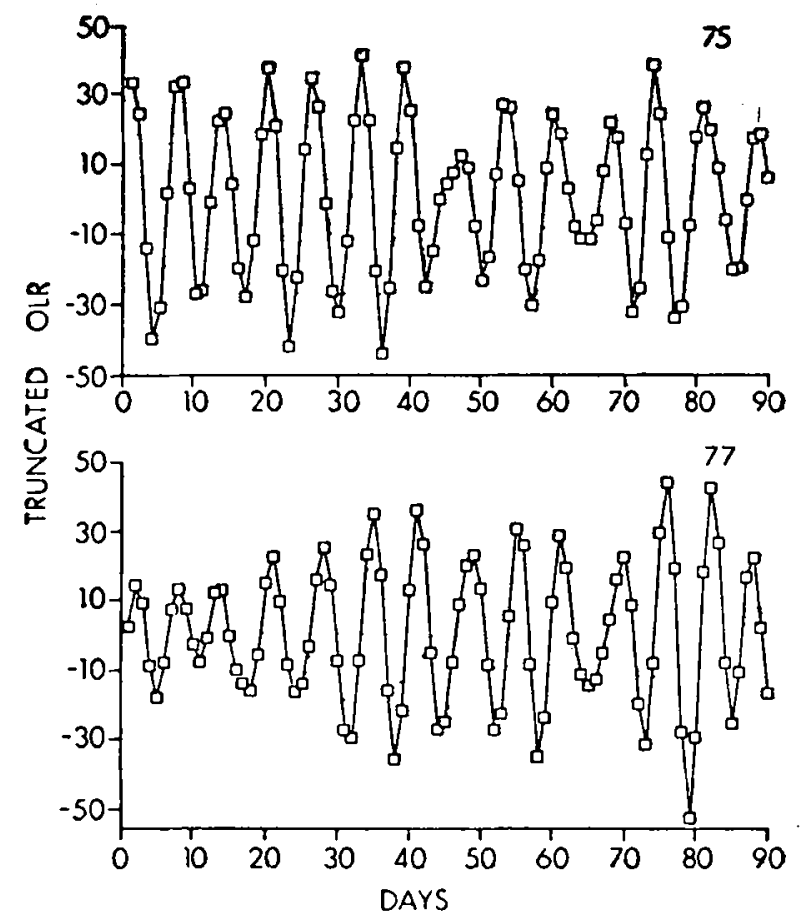

Figure 9. Time series of truncated (modes 1 to 10), 4-8 day filtered OLR at reference point $\left(17.5^{\circ} \mathrm{N}, 87.5^{\circ} \mathrm{E}\right)$ for summer 1975 (top) and summer 1977 (bottom).

Figures 10 and 11 show OLR anomaly patterns for categories 1, 3, 5 and 7 for summer 1975. Category 1 anomaly patterns are similar to the El pattern (figure 7, top). This justifies the appropriate selection of the reference point $\left(87 \cdot 5^{\circ} \mathrm{E}, 17 \cdot 5^{\circ} \mathrm{N}\right)$ for our study. Category 5 OLR configuration is nearly the same as that of category 1 except for a change of sign, which is consistent with the category definition. A weak negative anomaly situated over northeast Burma in category 1 intensifies as it moves over western Burma and the Andaman Seas in category 3, and attains the maximum intensity in the Bay of Bengal (category 5). This negative anomaly weakens as it moves over central India in category 7 , and reaches northwest India in category 1 . Likewise, all negative and positive anomaly centers propagate westward over the entire summer monsoon region. In figure 11 (top), trajectories of major OLR centers are plotted. It is clear'from the $; e$ trajectories that during summer 1975, OLR perturbations which originated in the Western Pacific propagated westward while weakening in intensity, and dissipated before reaching the Indochina coast. Almost concurrent with the arrival of this OLR disturbance over the Philippines at category 1, a new OLR disturbance formed over northeastern Burma, and moved westward, into the Bay of Bengal, where it reached maximum intensity (category 5). The westward phase speed of these OLR disturbances, as can be estimated from the trajectories, is about $3-4^{\circ}$ per day. 


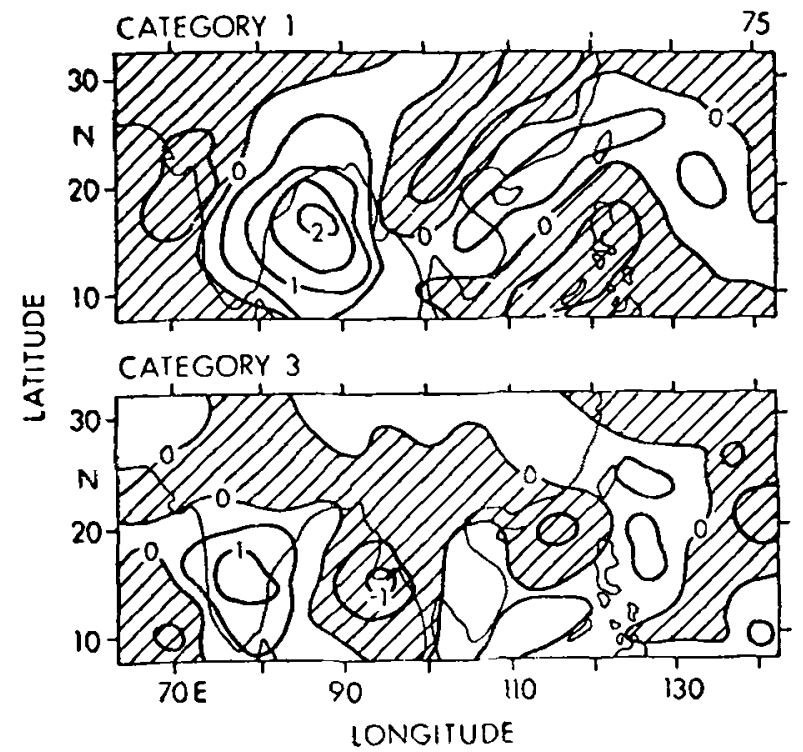

Figure 10. Composite maps of truncated 4-8 day filtered OLR anomalies for summer 1975. Category 1 (top) and category 3 (bottom). Negative anomalies are shaded.

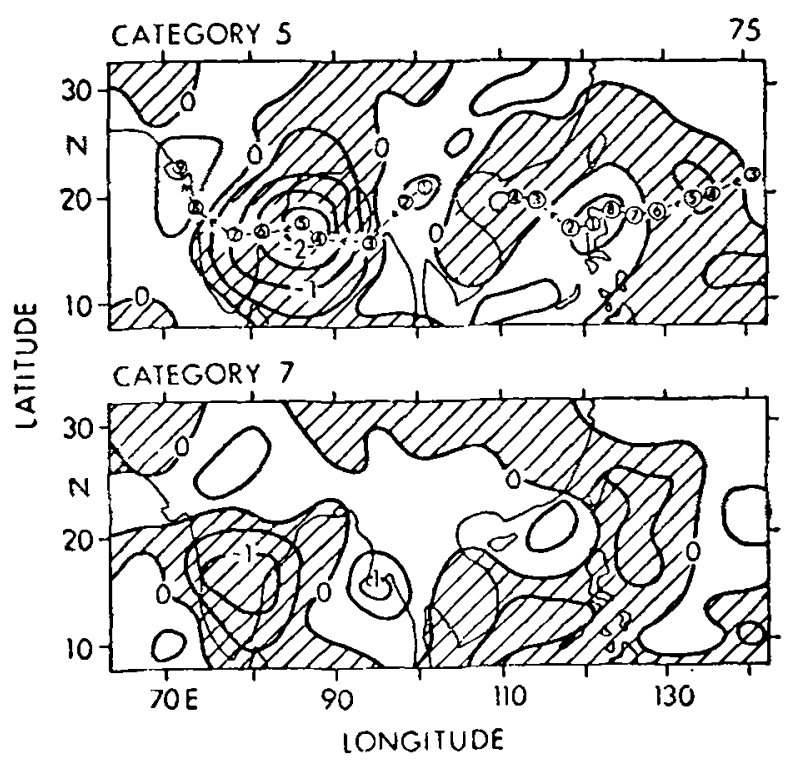

Figure 11. As in figure 10 except for category 5 (top) and category 7 bottom) The trajectories of major OLR anomaly centers are shown in the top diag am.

To avoid repetition of common features between summers 1975 and 1977 . only category 5 and category 7 are shown for summer 1977 . (figure 12). The rtajectory of OLR anomaly centers plotted in figure 12 (top) shows the cont- 


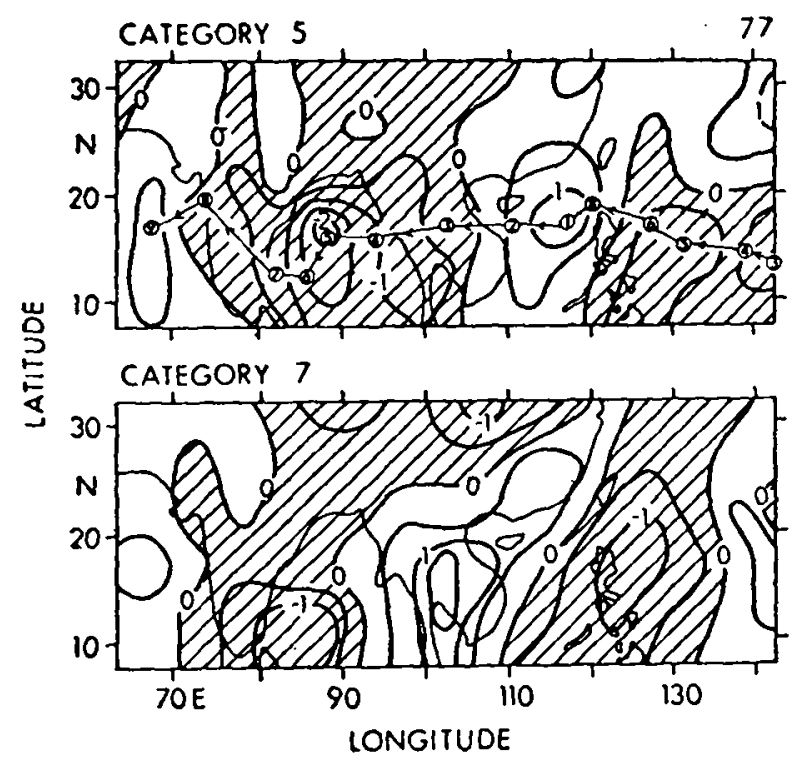

Figure 12. As in figure 11 except for summer 1977.

inuous propagation of OLR anomalies (disturbances) from the Western Pacific. across the northern border of the Philippines, the South China Sea and Indochina into the Bay of Bengal and beyond. Unlike summer 1975, there seems to be no significant weakening of disturbances as they move across the IndochinaSouth China Sea region in summer 1977. The phase speed is about $8^{\circ}$ longitude per day in confirmation with what was already found from lag-correlation diagrams in the previous section (figure 6).

The conception that monsoon depressions originate in situ over the Bay of Bengal has for long prevailed in the summer monsoon meteorological literature. Taking exception to this popular notion, a downstream amplification mechanism was proposed by Krishnamurti et al (1977) using 43 years of surface pressure data. They observed that westward moving disturbances came all the way from the Western Pacific to the Indian subcontinent. The results we have obtained here for summer 1977 agree qualitatively with the findings of Krishnamurti et al (1977). However, for summer 1975 the agreement is partial.

\section{Concluding remarks}

Despite the fact that both summers (1975 and 1977) have been considered as "good" monsoons, this study revealed large differences in the character of 4-8 day OLR disturbances between these two summers. During summer 1975, disturbance activity in the Bay of Bengal seems to have resulted from westward propagating short period (4-8 days) OLR disturbances which originated near northeastern Burma. In summer 1977, the short period westward moving disturbances evolved in the Western Pacific, crossed Indochina, and intensified in the Bay of Bengal. The wavelength and phase speed of 4-8 day OLR distru- 
bances in summer 1977 were approximately twice as large as in summer. 1975. The above results should be considered as preliminary, since they are based on only two years of summer data. A similar detailed study using many years of data should be carried out to clarify the year-to-year changes in the nature of summer monsoon disturbances.

Caution should be exercised while interpreting the results of this study because the data used here are filtered in space and time. OLR horizontal resolution $\left(2.5^{\circ}\right.$ latitude by $5^{\circ}$ longitude $)$ is not adequate to detail features with wave lengths less than $2,000 \mathrm{~km}$. Furthermore, the data constraint (one observation per day) makes the spectral peaks around two days statistically unreliable. Hence to eliminate these noise in space and time we deliberately subjected the daily data to filtering and truncation.

An assumption implicit in this study is that OLR data reflect the nature (convestive activity) of OLR disturbances. To clarify this point, a comparative study between OLR and wind fields has to be done. Perhaps, this problem can rest be investigated when the 1979 MONEX/FGGE data set becomes available.

\section{Acknowledgements}

The author is indebted to Dr T Murakami for his invaluable and constructive comments. He thanks Dr Murakami and Mr Steven Lyons for help in final editing of the manuscript.

This research has been supported by the National Oceanic and Atmospheric Administration, under grant No. 04-8-MoI-51, with Dr T Murakami as principal investigator. Partial financial assistances was also made by the National Science Foundation, under grant Nos. ATM 79-07255 and ATM-80-24881.

\section{References}

Ananthakrishnan R and Bhatia K L 1960 Symp. Monsoons of the World 157

Doraisamy Iyer V $1939 \mathrm{Mem}$. India Meteor. Dept. 26 pt. 6

Grimmer M 1963 Q. J. $R$ Meteor. Soc. 89395

India Meteorological Department 1964 Tracks of storms and depressions in the Bay of Bengal and the Arabian Sea. India Meteor. Dept. New Delhi p. 167

Keshavamurthy R N 1972 J. Atmos. Sci. 29993

Keshavamurthy R N 1973 Indian J. Meteor. Geophys. 24117

Koteswaram P and George C A 1958 Indian J. Meteor. Geophys. 99

Koteswaram P and George C A 1960 Symp. Monsoons of the World 145

Koteswaram P and Bhaskara Rao N S 1963 Aust. Meteor. Mag. 4162

Krishnamurti T N and Bhalme H N 1976 J. Atmos. Sci. 331937

Krishnamurti T N, Molinari J, Pan H L and Wong V 1977 Mon. Wea. Rev. 1051281

Kutzbach J E 1967 J. Appl. Meteor. 6791

Murakami M 1976 J. Meteor. Soc. Jpn. 5415

Murakami M 1979 Mon. Wea. Rev. 107994

Murakami T 1979 J. Meteor. Soc. Jpn. 57133

Murakami T 1980 Mon. Wea. Rev. 108 205, 408, 427

Paul D K and Sikka D R 1975 Sci. Rep. India Inst. Trop. Meteor., Poona

Pettersen S 1956 Weather analysis and forecasting (New York: McGraw Hill)

Raman C R V, Rao Y P and Alvi S M A 1980 Curr. Sci. 49123 
Shanks J L 1967 Geophysica 3233

Shukle I $1978 \mathrm{~J}$, Atmos, Sci, 35495

Sutclisffe R C 1947 Q. J. R, Meteor. Sac. 73370

Wallace I M 1970 ESS.4 Tech, Rep, NESE 56 U. S. Dept. of Commerce p, 37

Wallace J M and Chang C P 1969 J. Atmos, Sci. 761010

Weare B C 1977 Q. J. R, Metcor. Soc. 103467

Ząngil A 1975 Mon. Wea. Rev, 103,904 